\title{
Instrumentation and observation target of the Lunar Radar Sounder (LRS) experiment on-board the SELENE spacecraft
}

\author{
Takayuki Ono $^{1}$, Atsushi Kumamoto ${ }^{1}$, Yasushi Yamaguchi ${ }^{2}$, Atsushi Yamaji ${ }^{3}$, \\ Takao Kobayashi $^{4}$, Yoshiya Kasahara ${ }^{5}$, and Hiroshi Oya ${ }^{6}$ \\ ${ }^{1}$ Graduate School of Science, Tohoku University, Aoba-ku, Sendai 980-8578, Japan \\ ${ }^{2}$ Graduate School of Environmental Studies, Nagoya University, Furo-cho, Chikusa-ku, Nagoya 464-8601, Japan \\ ${ }^{3}$ Graduate School of Science, Kyoto University, Sakyo-ku, Kyoto 606-8502, Japan \\ ${ }^{4}$ Korea Institute of Geoscience \& Mineral Resources (KIGAM), Yuseong-gu, Daejeon 305-350, Korea \\ ${ }^{5}$ Information Media Center of Kanazawa University, Kanazawa 920-1192, Japan \\ ${ }^{6}$ Fukui University of Technology, Fukui 910-8505, Japan
}

(Received April 4, 2007; Revised October 22, 2007; Accepted November 6, 2007; Online published April 9, 2008)

\begin{abstract}
The Lunar Radar Sounder (LRS) on-board the SELENE lunar orbiter is currently being equipped to provide the data of subsurface stratification and tectonic features in the shallow part (several $\mathrm{km}$ deep) of the lunar crust, by using an FM/CW radar technique in $\mathrm{HF}(\sim 5 \mathrm{MHz})$ frequency range. Knowledge of the subsurface structure is crucial to better understanding, not only of the geologic history of the Moon, but also of the Moon's regional and global thermal history of the Moon and of the origin of the Earth-Moon system. In addition to the subsurface radar experiment, LRS will provide the spectrum of plasma waves and solar and planetary radio waves in a wide frequency range from $10 \mathrm{~Hz}$ to $30 \mathrm{MHz}$. This paper provides the basic function parameter of the LRS system based on the final function test and proposes observation targets and data analysis that will provide important information leading to a greater understanding of the tectonics and thermal history of the Moon.
\end{abstract}

Key words: Radar Sounder, HF radar, Moon, subsurface structure, tectonics, thermal history, planetary radio waves.

\section{Introduction}

For the purpose of studying the origin and evolution processes of the Moon, the SELENE mission will use remote sensing techniques from a polar orbit with an altitude of $100 \mathrm{~km}$. Knowledge of topographical features of the subsurface to a depth of several km below the surface, with a horizontal scale of several tens of $\mathrm{km}$, is necessary to understand the origin and evolution of the Moon because the topographical and geological features of the subsurface features are directly related to the history of lunar geology (Yamaji et al., 1998). Based on the results of the Apollo radar experiments carried out within two orbital tracks near the equatorial regions and other studies on lunar rocks and soils, it has been ascertained that the surface layer of the Moon consists of material with a median loss tangent of 0.008 (Olhoeft and Strangway, 1975; Strangway and Olhoeft, 1977). Therefore, electromagnetic waves in the HF range can penetrate into the lunar subsurface to a depth of several $\mathrm{km}$. When propagating radio waves encounter geological interfaces with sharp boundaries of permittivity, a partial reflection of the electromagnetic waves take place, generating subsurface echoes. Based on this concept, a radar sounder experiment ALSE (Apollo Lunar Sounder Experiment) on-board the Command and Service Module of the Apollo 17 was tested during several orbits (Phillips et

Copyright (C) The Society of Geomagnetism and Earth, Planetary and Space Sciences (SGEPSS); The Seismological Society of Japan; The Volcanological Society of Japan; The Geodetic Society of Japan; The Japanese Society for Planetary Sciences; TERRAPUB. al., 1973). The ALSE experiment verified that radar sounding using HF range electromagnetic waves can be used to explore the subsurface structure of the Moon, and these results provide important information for investigation of lunar tectonics within a depth of several km (Porcello et al., 1974; Sharpton and Head, 1982; Cooper et al., 1994). Since the termination of the Apollo missions, there have been no additional experiments using the radar sounder technique for the lunar subsurface exploration. A recent Mars Express mission was carried out for ice exploration on Mars using the HF radar sounder method (Picardi et al., 2005; Gurnett et al., 2005). Therefore, the Lunar Radar Sounder (LRS) is now being equipped to conduct a full mapping of lunar subsurface.

During the Apollo missions, there were technical limitations in space borne radar sounder techniques, especially due to the usage of a voltage controlled oscillator (VCO) and the low S/N ratio of the data stored by the analog (optical) data recording methods (Phillips et al., 1973; Peeples et al., 1978). In the present LRS system, a full digital controlled system makes it possible to generate waveforms of the transmitter and local signals for each transmission and reception of RF echoes. Generation of the transmitted RF pulse signal as well as the swept frequency local signal of the receiver is controlled by an identical clock generator within an accuracy of $10 \mathrm{nsec}$ and generated by using an A/D converter with 12 bit resolution. An optical recording on photo-film used by the ALSE had a limit of the dynamic range of about $25 \mathrm{~dB}$. In the LRS sys- 

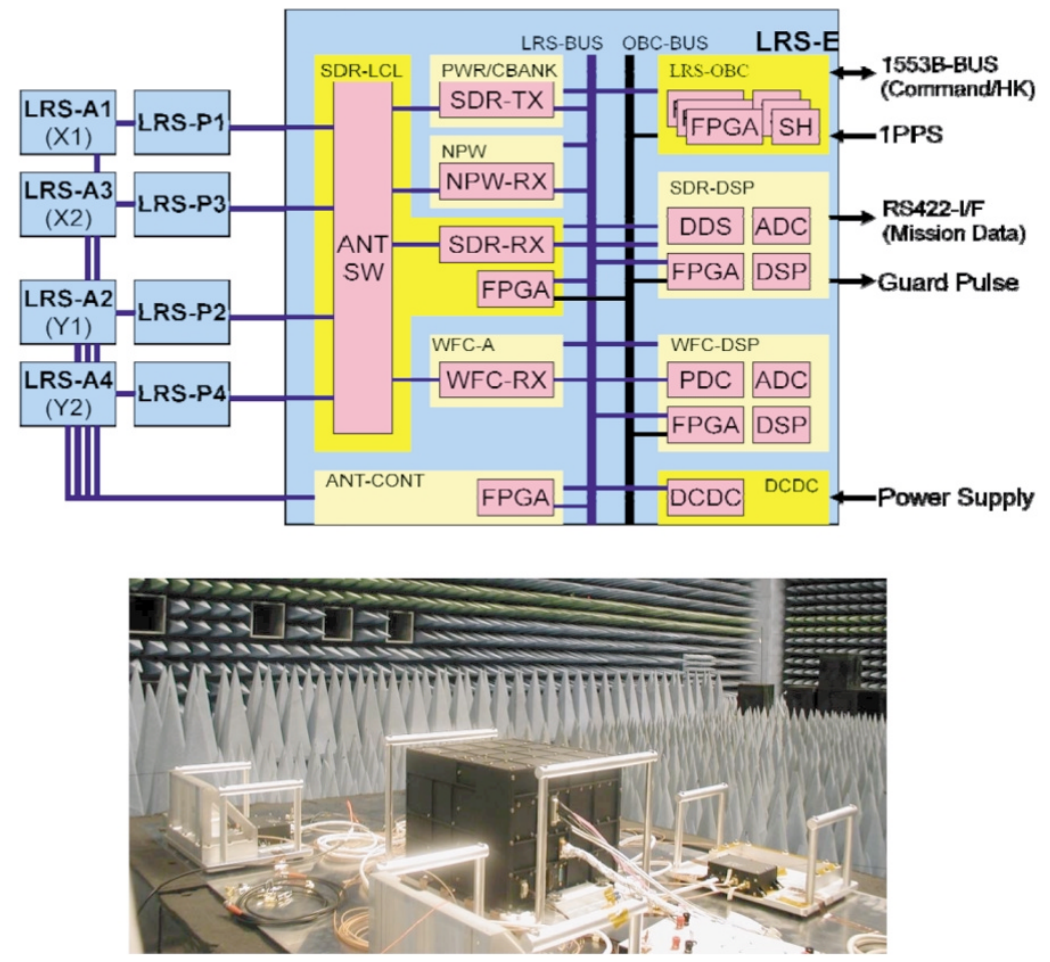

Fig. 1. A block diagram (a) and a view of the main electrical circuit unit of the LRS system (b). The LRS system consists of antennas (A1-A4), pre-amplifiers (P1-P4), and the main unit which contains the transmitter and the receiver of the sounder system, receivers of the natural plasma waves in high frequency range (NPW) and the wave form capture (WFC). The photo is taken during the EMC test of the LRS system in the electromagnetic shielded room of the Tsukuba Space Center.

tem the echo data has sufficient 12 bit resolution to be transmitted to the ground. Throughout the LRS system, we made improvements to the instrumentation by adopting new technology developed during plasma sounder experiments which were conducted on the Earth's magnetosphere, plasmasphere and ionosphere (Ono, 2005). The concept of the plasma sounder originates from the topside sounder satellites of Alouette and ISIS (Franklin and MacLean, 1969; Jackson et al., 1969); namely, the plasma sounder has capability of transmission of high power RF pulses into plasma through long dipole antennas. Detection of plasma sounder echo signals makes it possible to measure the plasma density profiles along the propagation path of sounder RF pulses. In addition to the sounder operation, the plasma sounder system has the additional function of observing the detailed features of natural plasma waves and planetary radio waves. The plasma sounder system was further developed for sounding of Martian ionosphere and land shape using the sounder experiment on-board the PlanetB (Nozomi) spacecraft (Ono et al., 1998; Oya and Ono, 1998). The present LRS system on-board the SELENE is also capable of sounder operation detecting subsurface echoes, and will also be able to observe the plasma waves generated near the Moon and radio wave emissions from Jupiter, the Sun, Earth, and other planets without intense man-made noise from the Earth. In April 2007, the SELENE spacecraft had already passed the system integration testing and had been transferred to the pre launch operation at the launch site. The SELENE spacecraft was launched on September 14, 2007. In this paper, instrumentation and cal- ibration of the sounder and observation mode for the LRS system are introduced in Sections 2 and 3, respectively, and the proposed set up for lunar observation is provided in Section 4. The limit and possible extension for the LRS data are discussed in Section 5.

\section{Instrumentation of LRS}

\subsection{Subsystem of the LRS instrument}

The Lunar Radar Sounder (LRS) has been designed to obtain subsurface structure information by using an HF radar sounding technique and spectra of natural emissions of radio and plasma waves in a wide frequency range from $10 \mathrm{~Hz}$ to $30 \mathrm{MHz}$ along the lunar orbit. As discussed by Ono and Oya (2000), the primary observation frequency for radar sounding selected was $5 \mathrm{MHz}$ with a frequency band width of $2 \mathrm{MHz}$. The usage of wide frequency bandwidth has become possible because there is no dispersion effect from propagating radio waves within this frequency range for the lunar observation compared with planetary sounding which is possibly affected by ionosphere plasma (Kobayashi and Ono, 2006). The natural radio and plasma waves are observed by using 2 receiver systems, NPW (Natural Plasma Waves) and WFC (Wave Form Capture: Kasahara et al., 2008), which cover from $20 \mathrm{kHz}$ to $30 \mathrm{MHz}$ and from $10 \mathrm{~Hz}$ to $1 \mathrm{MHz}$, respectively. As illustrated in Fig. 1(a), the LRS system consists of 4 sets of antennas $(\mathrm{A} 1(\mathrm{X} 1), \mathrm{A} 2(\mathrm{Y} 1), \mathrm{A} 3(\mathrm{X} 2), \mathrm{A} 4(\mathrm{Y} 2)), 4$ sets of preamplifiers (P1, P2, P3, P4) and the main unit (LRS-E) which contains the transmitter and receiver of the sounder experiment, receivers for natural plasma and radio waves 


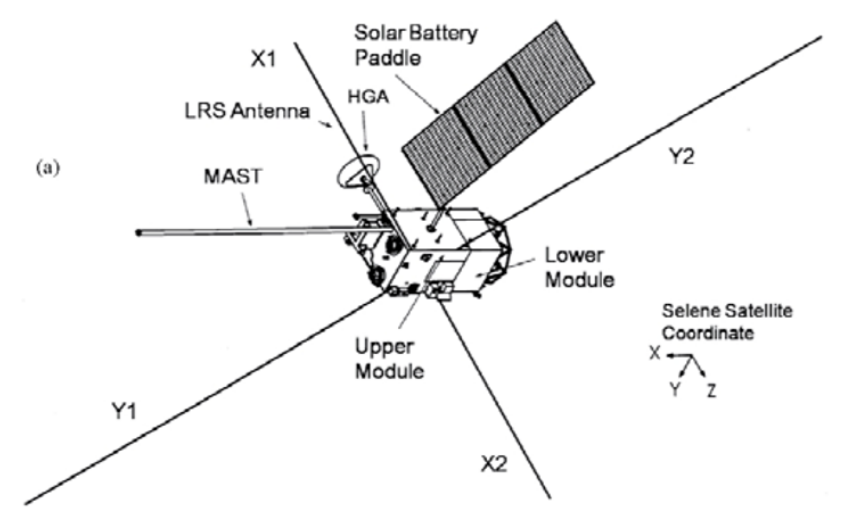

(b)

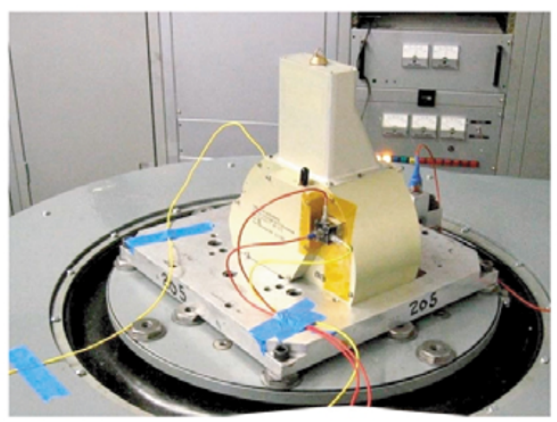

Fig. 2. The orientation of LRS antenna on-board the SELENE (a) and an out view of antenna driver unit when the unit is under the vibration test (b). In the standard observation period, the Z-axis of the SELENE coordinate is directed to the Moon. Four sets of the LRS antennas will be deployed from the Z-panel of the upper module of SELENE satellite.

in two frequency regions (NPW and WFC) and a data handling unit which controls operation of the LRS system. Figure 1(b) provides a view of the LRS units taken during the sounder system tests in an electro-magnetic shielded room. 2.2 The Antenna system

As shown in Fig. 2, X- and Y-antenna are defined to make a rectangular coordinate whose $\mathrm{Z}$-axis is directed to the Moon surface. Table 1 summarizes the electrical and mechanical properties of the LRS system. The antenna pairs of X1-X2 and Y1-Y2 form an X- and Y-dipole antenna system, respectively. Four units of LRS antennas are designed to have identical electrical and mechanical characteristics. The interlocked BiStem antenna element on-board the SELENE is made of 2 sheets of $\mathrm{BeCu}$ alloy material with a thickness and length of $51 \mu \mathrm{m}$ and $15 \mathrm{~m}$, respectively. When the antenna is deployed, 2 pieces of thin metal sheets automatically form a very stiff column of more than $155 \mathrm{kgf} / \mathrm{cm}^{2}$, with a diameter of $12.5 \mathrm{~mm}$ and a length of $15 \mathrm{~m}$. To avoid any damage to the elements due to acceleration during maneuvering of the SELENE, whose maximum level after operation of antenna deployment was estimated to be about $0.01 \mathrm{~g}$, a guiding extension roller is located at the end of the driver unit with an allowable bending moment of $1.4 \mathrm{~N} \mathrm{~m}$. Performance of the antenna system has been verified through a functional and environmental test of the antenna for all anticipated conditions, such as vibration and shock at the launch time, thermal vacuum condition at the antenna deployment, and acceleration due to the thruster operation for maneuvering of the spacecraft. Figure 2(b)
Table 1. Physical and electrical properties of the LRS system on-board the SELENE satellite.

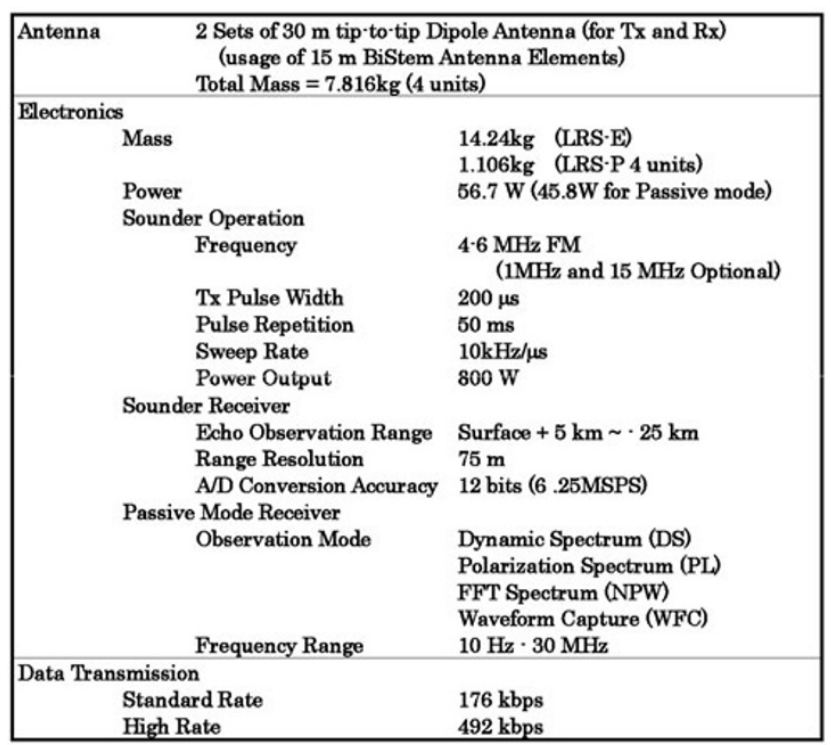

provides an outer view of a section of antenna during the vibration test.

\subsection{Observation modes}

The operation of the LRS system has two functions: passive mode (NPW mode) and active mode (SDR; sounder mode). Table 2 shows the major LRS observation modes during standard operation. These include:

(1) NPW DS mode: Observation of frequency spectra of natural waves obtained by $\mathrm{X}$, and $\mathrm{Y}$ antennas.

(2) NPW PL mode: Observation of polarization spectra of natural waves by using signals detected by $\mathrm{X}$ and $\mathrm{Y}$ antennas simultaneously.

(3) NPW WX mode: Observation of waveform of natural waves in high frequency detected by $\mathrm{X}$-antenna within a frequency range of $20 \mathrm{kHz}-10 \mathrm{MHz}$.

(4) NPW WY mode: Observation of waveform of natural waves in high frequency detected by Y-antenna within a frequency range of $20 \mathrm{kHz}-10 \mathrm{MHz}$.

(5) SXY HR mode: Sounder observation while transmitting from $\mathrm{X}$-antenna and receiving from Y-antenna. The echo data are obtained and transmitted to the ground as a waveform.

(6) SXX HR mode: Sounder observation while transmitting and receiving via $X$-antenna by using the TR (Transmitter Receiver) switch. The echo data are obtained and transmitted to the ground as a waveform.

(7) SYX HR mode: Sounder observation while transmitting from Y-antenna and receiving from X-antenna. The echo data are obtained and transmitted to the ground as a waveform.

(8) SYY HR mode: Sounder observation while transmitting and receiving via Y-antenna by using the TR switch. The echo data are obtained and transmitted to the ground as a waveform.

(9) SXY LR mode: Sounder observation while transmitting from $\mathrm{X}$-antenna and receiving from Y-antenna. The echo signals are transmitted to the ground as 
Table 2. Observation modes of standard operation for the LRS system.

\begin{tabular}{|c|c|c|c|c|c|c|c|c|}
\hline \multirow{3}{*}{\multicolumn{2}{|c|}{$\begin{array}{c}\text { Observation Mode and } \\
\text { Data }\end{array}$}} & \multicolumn{3}{|c|}{ NPW } & \multirow{4}{*}{$\frac{\text { WFC }}{0}$} & \multicolumn{2}{|c|}{ SDR } & \multirow{4}{*}{$\begin{array}{c}\begin{array}{c}\text { Data } \\
\text { Rate }\end{array} \\
176 \mathrm{kbps}\end{array}$} \\
\hline & & \multirow{3}{*}{$\begin{array}{c}20 \mathrm{kHz}-30 \mathrm{MHz} \\
\text { Spectrum } \\
0\end{array}$} & \multicolumn{2}{|c|}{$20 \mathrm{kHz}-10 \mathrm{MHz}$} & & \multirow{3}{*}{ Spectrum } & \multirow{3}{*}{ Waveform } & \\
\hline & & & \multirow[t]{2}{*}{ Waveform } & \multirow{2}{*}{ Spectrum } & & & & \\
\hline NPW-DS & $\begin{array}{l}\text { Dynamic } \\
\text { Spectrum }\end{array}$ & & & & & & & \\
\hline NPW-PL & $\begin{array}{l}\text { Polarization } \\
\text { Spectrum }\end{array}$ & 0 & & & 0 & & & $176 \mathrm{kbps}$ \\
\hline NPW-W-X & $\begin{array}{c}\text { HF } \\
\text { Waveform } \\
\text { X-Antenna }\end{array}$ & & 0 & & 0 & & & $492 \mathrm{kbps}$ \\
\hline NPW-W-Y & $\begin{array}{c}\text { HF } \\
\text { Waveform } \\
\text { Y-Antenna }\end{array}$ & & 0 & & 0 & & & 492kbps \\
\hline SXY-HR & $\begin{array}{c}\text { SDR } \\
\text { Waveform } \\
\text { XY-Antenna }\end{array}$ & & & 0 & 0 & & 0 & $492 \mathrm{kbps}$ \\
\hline SXX-HR & $\begin{array}{c}\text { SDR } \\
\text { Waveform } \\
\text { XX-Antenna }\end{array}$ & & & 0 & 0 & & 0 & $492 \mathrm{kbps}$ \\
\hline SYX-HR & $\begin{array}{c}\text { SDR } \\
\text { Waveform } \\
\text { YX-Antenna }\end{array}$ & & & 0 & 0 & & 0 & $492 \mathrm{kbps}$ \\
\hline SYY-HR & $\begin{array}{c}\text { SDR } \\
\text { Waveform } \\
\text { YY-Antenna }\end{array}$ & & & 0 & 0 & & 0 & $492 \mathrm{kbps}$ \\
\hline SXY-LR & $\begin{array}{c}\text { SDR } \\
\text { Spectrum } \\
\text { XY-Antenna }\end{array}$ & & & 0 & 0 & 0 & & $176 \mathrm{kbps}$ \\
\hline SXX-LR & $\begin{array}{c}\text { SDR } \\
\text { Spectrum } \\
\text { XX-Antenna }\end{array}$ & & & 0 & 0 & O & & $176 \mathrm{kbps}$ \\
\hline SYX-LR & $\begin{array}{c}\text { SDR } \\
\text { Spectrum } \\
\text { YX-Antenna }\end{array}$ & & & 0 & 0 & 0 & & $176 \mathrm{kbps}$ \\
\hline SYY-LR & $\begin{array}{c}\text { SDR } \\
\text { Spectrum } \\
\text { YY-Antenma }\end{array}$ & & & 0 & 0 & 0 & & $176 \mathrm{kbps}$ \\
\hline
\end{tabular}

power spectrum data.

(10) SXX LR mode: Sounder observation while transmitting and receiving from $\mathrm{X}$-antenna by using the TR switch. The echo signals are transmitted to the ground as power spectrum data.

(11) SYX LR mode: Sounder observation while transmitting from Y-antenna and receiving from $\mathrm{X}$-antenna. The echo signals are transmitted to the ground as power spectrum data.

(12) SYY LR mode: Sounder observation while transmitting and receiving from Y-antenna by using the TR switch. The echo signals are transmitted to the ground as power spectrum data.

Within the observation time of the above modes, WFC observation in a low frequency region may be carried out simultaneously. Also, during the observation of SXY-LR, SXX-LR, SYX-LR, and SYY-LR modes, the waveform of natural waves is detected in digital form and transferred as frequency spectra to the ground after the on-board FFT (Fast Fourier Transformation) analysis with the data transfer speed of $176 \mathrm{kbps}$.

\subsection{Sequence of the sounder observation}

Figure 3 shows the schematic view of the sounder observation sequence. One of the most important system parameters with respect to the timing is the sequence of the sounder operation that is performed every $50 \mathrm{msec}$. As shown in Fig. 3(a), at the start of the sequence $(T=0)$, waveform data are generated from the 5000 word memory, transferred to the D/A converter, and then directly fed into the power amplifier with a pulse width of $200 \mu \mathrm{sec}$, and a frequency sweep from $4 \mathrm{MHz}$ to $6 \mathrm{MHz}$. Based on the orbital param- eter, the time of echo detection $(t)$ is expected to be within an accuracy of

$$
\tau_{0}<t<\tau_{0}+100(\mu \mathrm{sec}) .
$$

After the pulse transmission, the swept frequency local signal from $4 \mathrm{MHz}$ to $8 \mathrm{MHz}$ is started with the same sweep rate of $10 \mathrm{kHz} / \mu \mathrm{sec}$ being read out from the memory with the size of succeeding 10,000 words as shown in Fig. 3(b). The parameter $t$ represents the delay times for the echo from the lunar surface and subsurface boundaries. They are given as $\tau_{1}$ and $\tau_{2}$, respectively in Fig. 3(a). Because the altitude of the SELENE satellite is expected to be $100 \mathrm{~km}$ along the polar orbit, the expected arrival time of the echoes is within a range of $600 \mu \mathrm{sec}$. As a result, most of the sounder operation in each pulse transmission is completed within $1 \mathrm{msec}$. When the TR switch operation is used, the time period of the TR switch signal (designed as $250 \mu \mathrm{sec}$ ) covers the time period of the sounder pulse transmission. And immediately after the transmission, the antenna should be connected with the receiver and isolated from the power amplifier.

\subsection{TR switch and power amplifier}

For sounder observations using the same dipole antenna, a TR switch (Transmitter Receiver switch: Franklin and MacLean, 1969) is used. The TR switch works by switching-OFF the receiver form the antenna as well as the power amplifier with a time period of $250 \mu \mathrm{sec}$ that includes the time period of the sounder pulse width of $200 \mu \mathrm{sec}$ when the power amplifier is turned on. In the other time period, the TR switch is connecting the sounder receiver to the antenna. To protect the sounder receiver from the high 


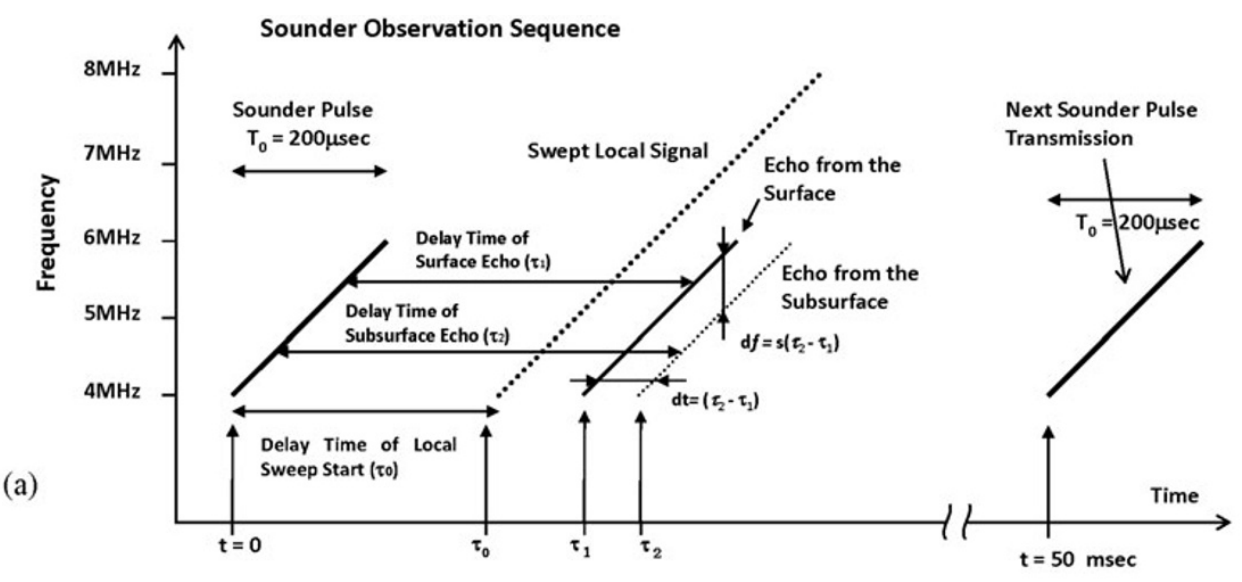

(b)

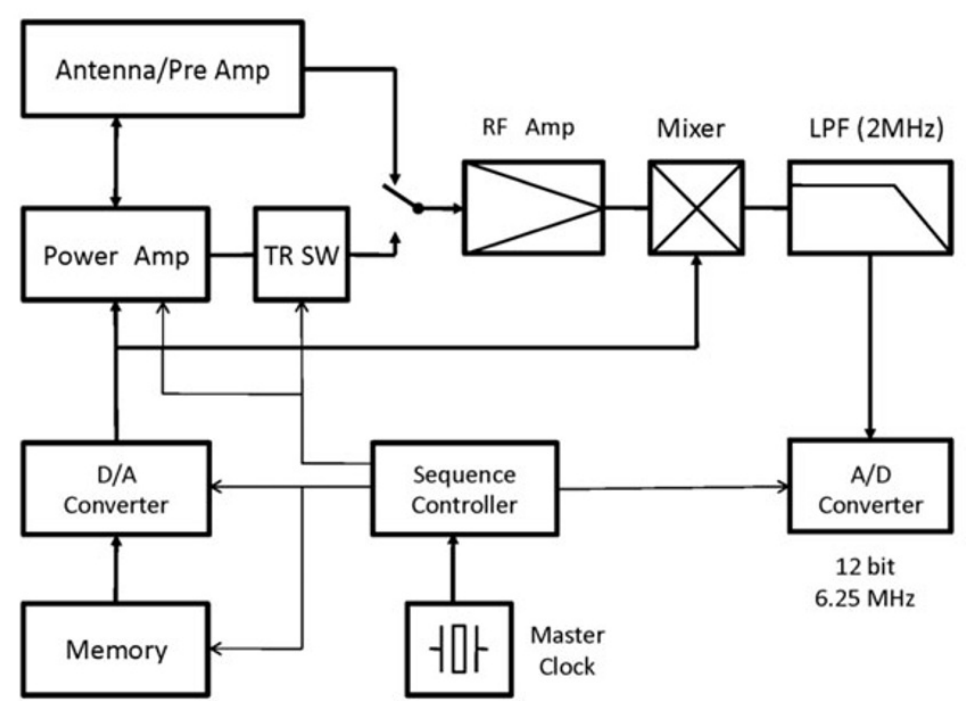

Fig. 3. A schematic view of the sounder observation sequence (a) and a block diagram to control the sounder sequence (b). In panel (b), thick lines and arrows indicate the flow of signals and thin lines and arrows show sequence control sounder pulse transmission every $50 \mathrm{msec}$.

voltage RF signal of the power amplifier (about $1000 \mathrm{Vpp}$ for the maximum value), the switching diode has to have a high break-down voltage with high resistance and low capacitance characteristics for the inverse bias condition. At the same time, the diode has to have a low impedance characteristic for the forward bias condition. For this purpose, UM7010B was selected as the switching diode of the TR switch. The insertion loss of the TR switch is basically determined by the ON-resistance of the switching diodes that are controlled by the bias currents fed to the diodes, which has been measured as $13 \mathrm{~dB}$. To obtain low insertion loss characteristics of the TR switch, the diode bias current of several $\mathrm{mA}$ for each diode is required, which is relatively large current for the small size step-up transformer because it requires more than 3000 turns for the 2 nd coil to realize output voltage of about $500 \mathrm{~V}$ and pulse width of $250 \mu \mathrm{sec}$. To avoid magnetic saturation due to the DC current, the core material of the transformer was selected as FPQ3220 (with 2500B material) which is able to keep high permeability under a high bias current of 30 AT. Figure 4 shows the circuit diagram of a unit of power amplifier (a), the final output stage of the main power amplifier by using 4 power amplifier units and antenna selection switch (b), and the TR switch (c).

\subsection{Performance of the power amplifier}

As is shown in Fig. 4(a), one unit of the power amplifier consists of a transformer coupled push-pull AB class amplifier. Due to the AB class operation and lossy transformer coupling, the efficiency of the power amplifier is about $25 \%$; however, it shows very strong and stable characteristics for any load condition from zero to infinite impedance. At the final stage of the main power amplifier, 4 units of amplifier work in parallel with the push-pull operation as shown in Fig. 4(b). Due to the frequency dependence of the dipole antenna impedance within a frequency range from $4 \mathrm{MHz}$ to $6 \mathrm{MHz}$ in free space, we selected standard load impedance of $100 \mathrm{ohms}$ for the evaluation of the power amplifier. Figure 5 shows an example of the waveform output obtained in the environmental test from the power amplifier when the load impedance is set as $50 \mathrm{ohms}$ for each terminal. The output peak amplitudes of $300 \mathrm{~V}$ and $305 \mathrm{~V}$ are obtained for each resistance; namely, in this case, the output powers of 225 Watts and 232 Watts for each load resistances are obtained. The total power becomes 457 Watts for the load impedance of $100 \mathrm{ohms}$. When we take into account the variation of antenna impedance $\left(Z_{a}\right)$ and antenna gain within the frequency range of LRS observation, the radiation power from the LRS system is able to be examined. 
(a)

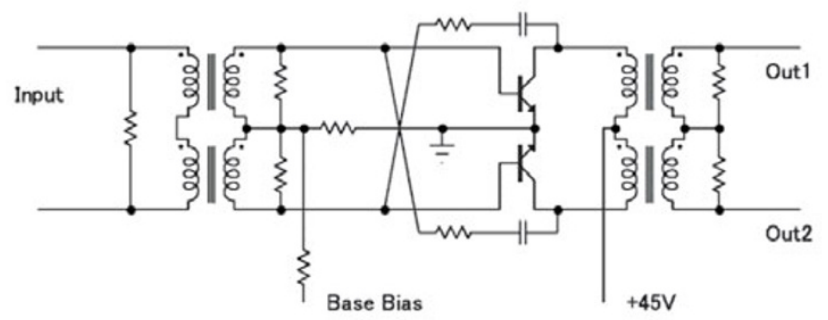

(b)

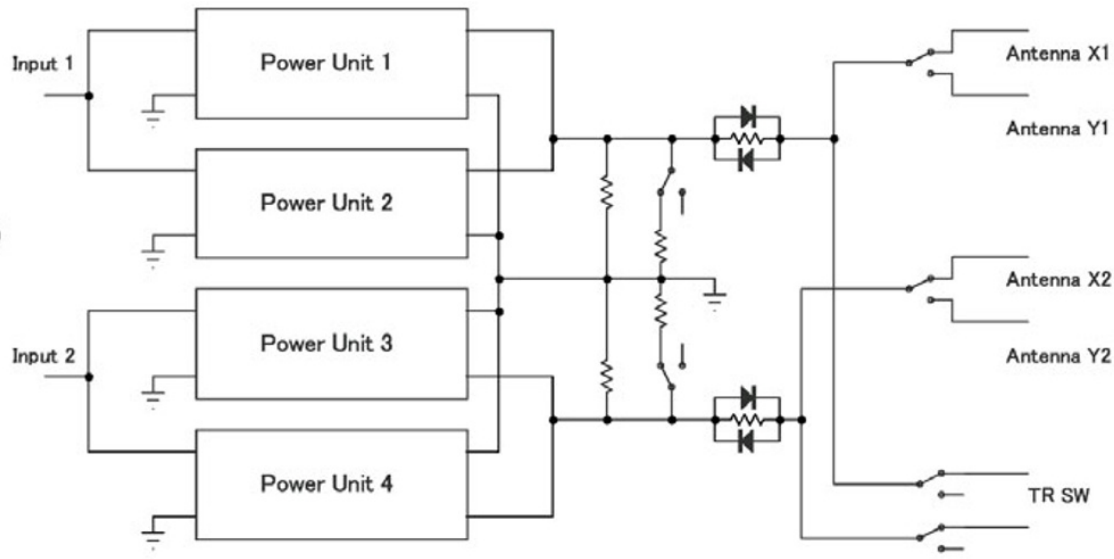

(c)

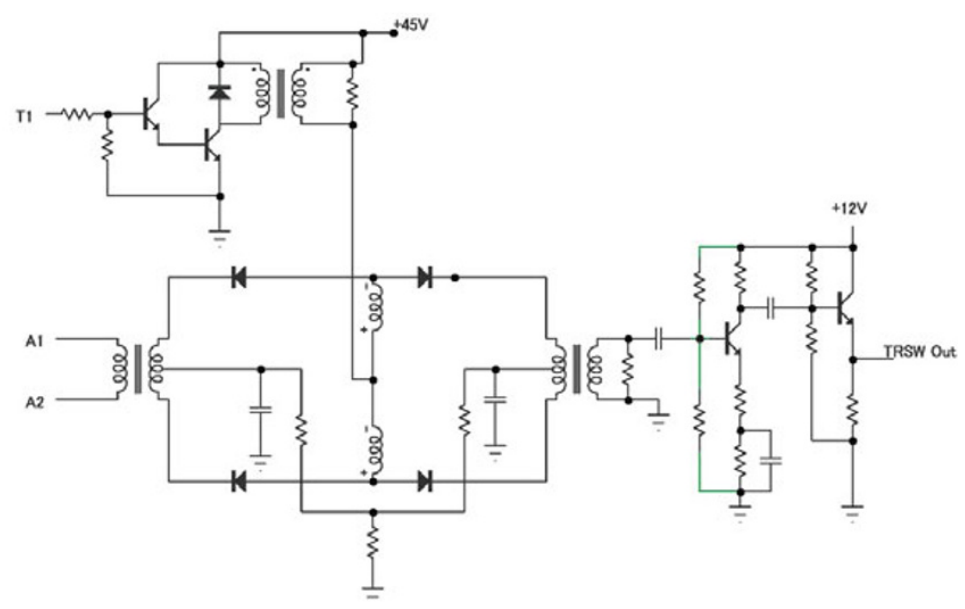

Fig. 4. A circuit diagram of power amplifier unit (a), the final output stage of the main power amplifier using 4 power amplifier units and an antenna selection switch (b), and the TR switch (c). To generate 800 Watts sounder RF pulses, the final stage of the main power amplifier consists of 4 units of the power amplifier given in (a).

$Z_{a}$ is a complex value with resistance and reactance parts of the antenna impedance described as:

$$
Z_{a}=Z_{r}+i Z_{i}
$$

As shown in Fig. 6(a), the LRS dipole antenna changes its impedance depending on the frequency. Taking into account the antenna gain of the dipole antenna as well as the antenna impedance, estimated radiation power from the LRS system is given in Fig. 6(b). As shown in Fig. 6(b), the peak power of the LRS sounding pulse is estimated as 753 Watts. It is noted that the frequency spectrum of the radiation power is concentrated within the frequency range of about $750 \mathrm{kHz}(-3 \mathrm{~dB})$. Then, when we take into account the effective radiation power spectrum of the sounder pulses, the spatial resolution of the sounder observation is estimated about $200 \mathrm{~m}$.

\subsection{On-board data analysis}

The envelope of the output RF pulse shape clearly shows the effect of the envelope function. The transmission signal waveform is described as a function of time, as

$$
T_{X}(t)= \begin{cases}0 & t<0 \\ a(t) \cos \phi(t) & 0 \leq t \leq T_{0} \\ 0 & T_{0}<t\end{cases}
$$

where

$$
\phi(t)=\left(\omega_{0}+\frac{1}{2} s t\right) t
$$

Variables $\omega_{0}, s$ and $a(t)$ are the starting angular frequency $\left(2 \pi \times 4 \times 10^{6} \mathrm{rad} / \mathrm{sec}\right.$ is selected for the LRS system), the sweep rate of angular frequency $\left(2 \pi \times 10^{10} \mathrm{rad} / \mathrm{sec}^{2}\right)$, and a 
(a)

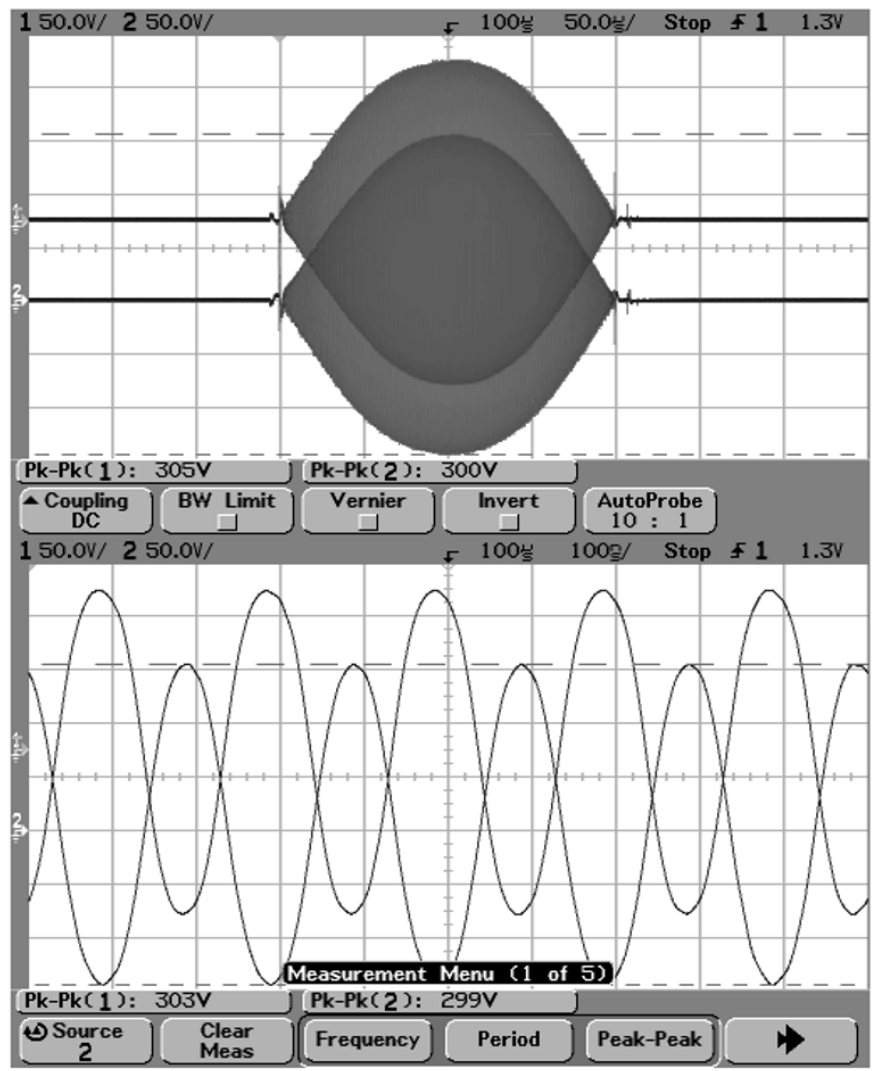

Fig. 5. Examples of an waveform envelope (a) and a fine signal shape (b) of the power amplifier output for $50 \mathrm{ohm}$ load impedance of each channel.

pulse shape function to define the envelope for transmitted RF pulses, respectively; and $T_{0}$ in Eq. (2) gives the sounder pulse width (200 $\mu \mathrm{sec}$ for the LRS system). For the shape function we selected a sine function described as:

$$
a(t)=\sin \left(\pi \times \frac{t}{T_{0}}\right)
$$

As has already been discussed by Ono and Oya (2000), the pulse compression technique was used in the pulse transmission, reception and data analysis. In the LRS observation, the transmitted signal is swept in frequency from $4 \mathrm{MHz}$ to $6 \mathrm{MHz}$ within the pulse period of $200 \mu \mathrm{sec}$. This pulse compression technique realizes an equivalent pulse width of about $0.5 \mu \mathrm{sec}$ which makes it possible to obtain the high spatial resolution of about $150 \mathrm{~m}$ for the detection of delayed echo signal reflected from the surface or subsurface of the Moon. As discussed by Ono and Oya (2000), the conversion from a frequency resolution $(\delta \omega)$ to a corresponding distance $(\delta z)$ can be obtained as,

$$
\delta z=\frac{c}{2 \sqrt{\varepsilon_{1}}} \frac{\delta \omega}{s},
$$

where $\varepsilon_{1}, c$, and $s$ are the relative dielectric constant of the surface material, the speed of light, and the sweep rate of angular frequency $\left(2 \pi \times 10^{10} \mathrm{rad} / \mathrm{sec}^{2}\right)$, respectively. Based on the sampling theorem, the frequency resolution of Fourier analysis can be estimated as a function of the datasampling period equal to the period of pulse transmission; therefore, the theoretical limit is $5 \mathrm{kHz}$ for the present LRS system.
The echo signals picked up by using the dipole antenna are mixed with the local signal swept from $4 \mathrm{MHz}$ to $8 \mathrm{MHz}$; the sounder receiver signal is obtained after passing through the $2 \mathrm{MHz}$ low pass filter and being converted to a digital form, as is shown in Fig. 3(b). Based on the model calculation of signal levels for surface and subsurface echoes (Ono and Oya, 2000), the necessary dynamic range of the receiver is estimated to be more than $60-70 \mathrm{~dB}$. To realize this requirement, the linearity of the transmitted pulse waveform and receiver should cover this dynamic range. We used 12 bit resolution for signal processing which makes it possible to realize the dynamic range of $72 \mathrm{~dB}$. The linearity of the waveform synthesis in the transmission pulse and swept frequency local signal is achieved by using 12 bit D/A converter as described in Section 2.4. In the receiver, an A/D converter with a sampling speed of 6.25 MHz and an amplitude resolution of 12 bit is used for this purpose. To adjust the signal level, a gain control is performed in the analog circuit beforehand, by applying attenuation of $-0 \mathrm{~dB}$ (high-gain), $-15 \mathrm{~dB}$ (medium gain) and $-30 \mathrm{~dB}$ (low gain). The A/D conversion is accomplished within the time period of $400 \mu \mathrm{sec}$ with a sampling clock of $160 \mathrm{nsec}$ that generates 2500 words of the sounder data. To minimize the amount of data transmission to the ground, 2048 words are selected and transferred to the ground as a waveform of an echo. The waveform data require high speed data transmission with a speed of $492 \mathrm{kbps}$. When the resource of telemetry is strictly limited, the power spectrum data after analyzing with fast Fourier transformation on-board are transferred to the ground for 320 frequency 
(a)

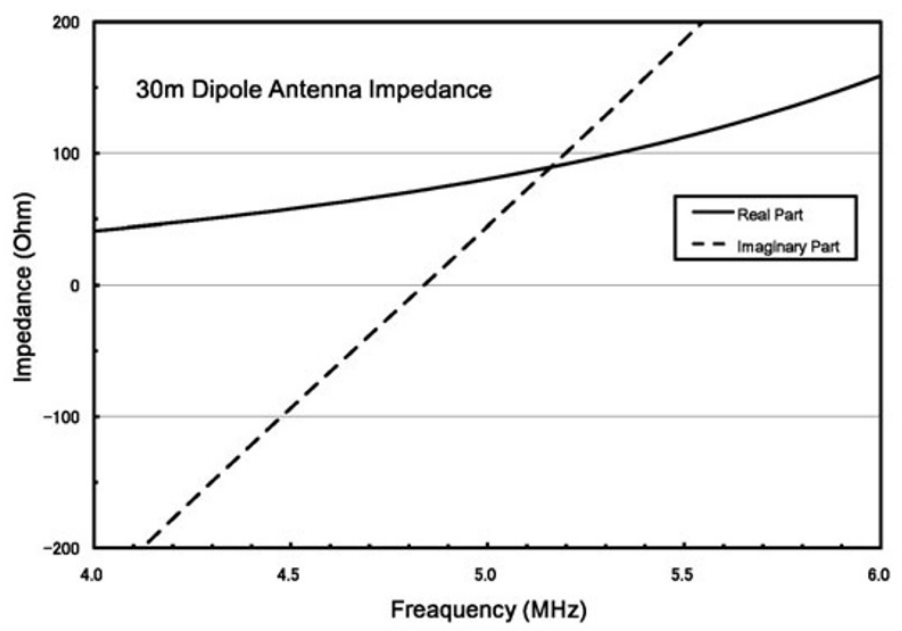

(b)

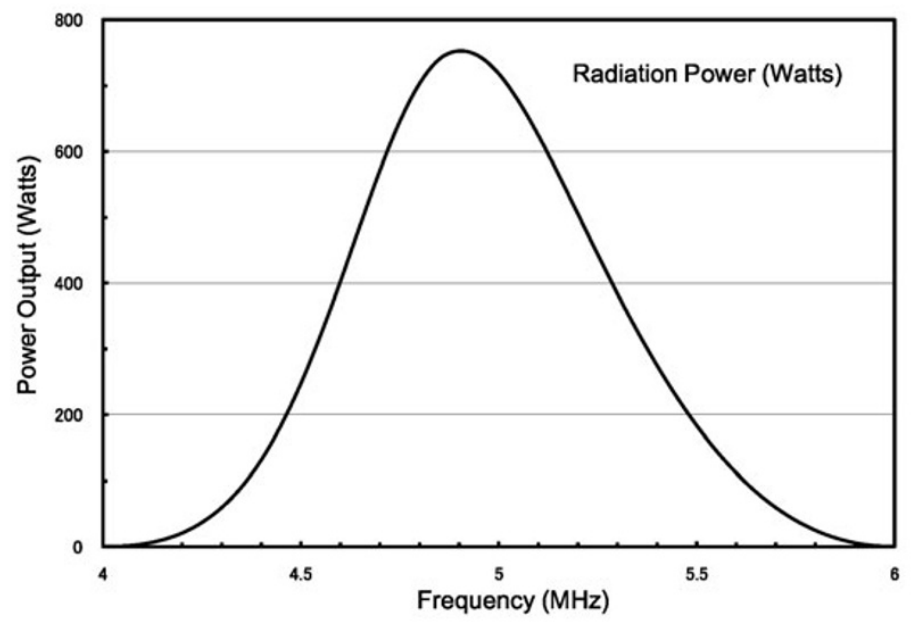

Fig. 6. An estimated antenna impedance in the vacuum condition (a), and an estimated radiation power of the transmitted pulse (b). Solid and broken curves in (a) give real and imaginary part of the antenna impedance, respectively.

steps with 12 bit logarithmic data form. In this case, the $176 \mathrm{kbps}$ data transmission speed is enough to transfer the sounder data and WFC data at the same time. However, to achieve higher order data analysis of the LRS data, such as the synthetic aperture radar (SAR) method, waveform data transmission is necessary.

\section{Calibration of the Sounder System}

The calibration of the overall sounder observation is carried out by using a delay circuit which simulates delayed echo signals that are returned from the lunar surface as well as subsurface boundaries. The delay circuit consists of fast speed A/D converter, FIFO (First In First Out) memory and $\mathrm{D} / \mathrm{A}$ converter. The delay time is precisely controlled by adjusting the delay clock number of the data read out fed to the D/A converter. Figure 7 provides a schematic set up of LRS components and echo simulation for the calibration of the LRS system for the SXY or SYX mode sounder operation. As shown in Fig. 7, output power signals are fed to the delay circuit where the delay time is set with a time unit of $40 \mathrm{nsec}$. For example, a delay time set of $660 \mu \mathrm{sec}$ is applied for simulating echoes from the distance of $100 \mathrm{~km}$. When the start time of the local sweep signal inside the LRS-E is set as $650 \mu$ sec from the sounder pulse transmission, there is a frequency difference of $100 \mathrm{kHz}$ between these signals, and finally, the receiver output signal has a frequency of $100 \mathrm{kHz}$ appearing in the final waveform data as shown in panel (c) of Fig. 7. The sampling speed of the waveform data is $6.25 \mathrm{MHz}$ at the A/D conversion; the waveform data with a word length of 2048 have a time period of $327.68 \mu \mathrm{sec}$. Figure 7(c) shows an example of the waveform data transmitted to the ground when the data transmission rate of $492 \mathrm{kbps}$ is obtained. In this case, when the data transmission period is 2048 words with 12 bit resolution, then the most favorable data are available on the ground. A similar configuration is also used for the SXX or SYY mode sounder operation.

Figure 8 shows an example of data analysis in the SXXHR calibration mode, with data transmitted via the high speed telemetry format. The transmitted waveform data are analyzed with FFT analysis on the ground based on a computer system. The delay time of the local signal programmed in the LRS-E and echo delay time set up in the echo simulator are set as $560 \mu \mathrm{sec}$ and $579.6 \mu \mathrm{sec}$, respectively. In this case, the sounder receiver output signal has a frequency of $196 \mathrm{kHz}$, corresponding with a $19.6 \mu \mathrm{sec}$ 
(c)

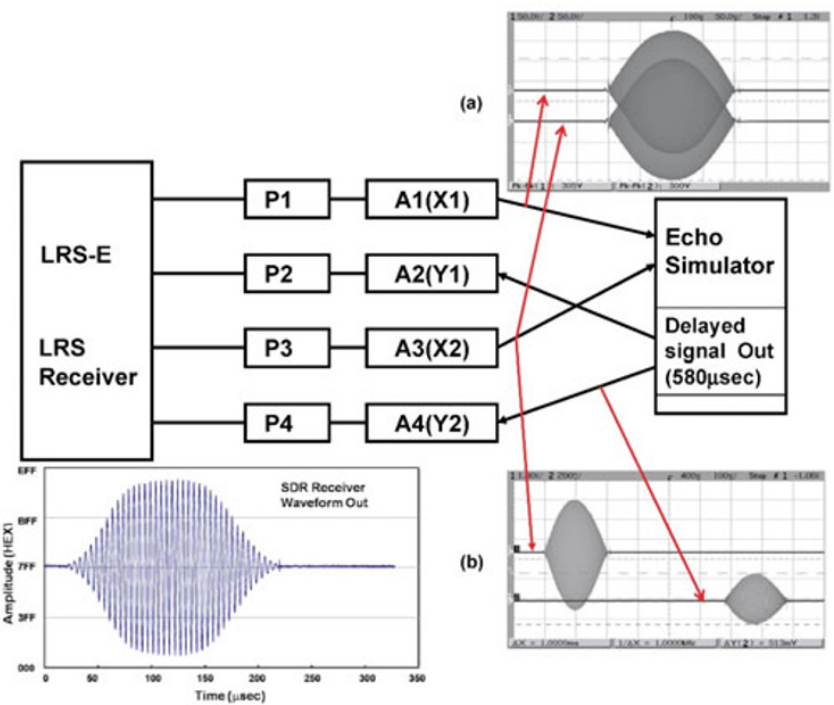

Fig. 7. An instrumental set up and typical examples of waveforms during the sounder calibration of the LRS system. The output signals of the sounder RF pulses are fed to the echo simulator (panel (a)) which is able to generate delayed signal for the input waveform with delay time step of 40 nsec (panel (b)). Inside the sounder receiver of the LRS-E, a picked up echo signal is mixed with the swept local signal and obtained as the sounder receiver's output signal as shown in the panel (c).

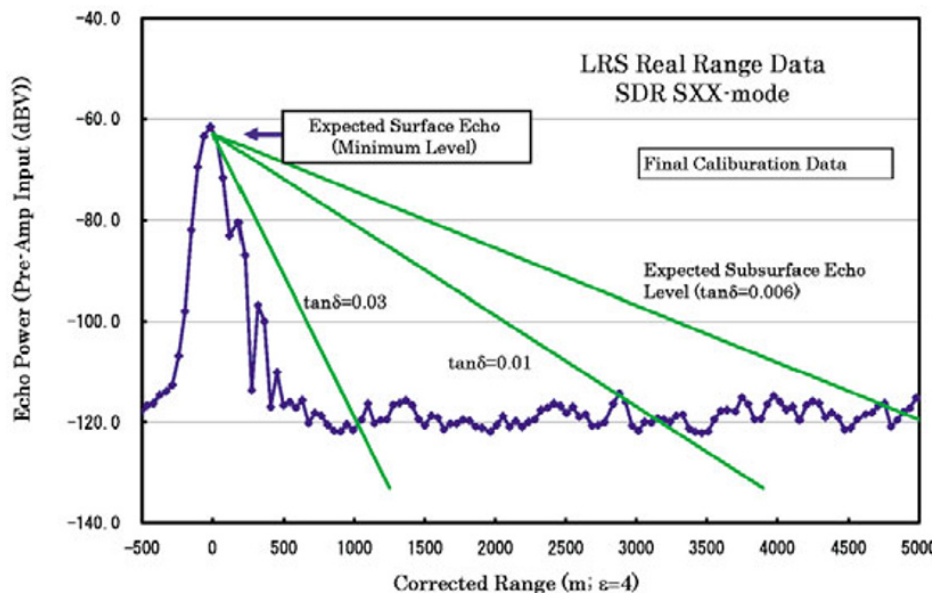

Fig. 8. A typical example of the result of the sounder echo analysis displayed as the A-scan display format (Kobayashi et al., 2002a). As shown in the figure, the background noise of the sounder receiver is obtained as about $-120 \mathrm{~dB} \mathrm{~V}$ that is well enough to detect the surface echoes from the Moon. The green lines give an expected subsurface echo intensity depending on the loss tangent value of the surface material as well as depth of the subsurface boundaries. As shown in this figure, subsurface echoes from the depth of $5000 \mathrm{~m}$ are detectable when propagation medium has low loss tangent value of 0.006 .

delay. The horizontal axis of Fig. 8 shows the frequency range of 160 to $530 \mathrm{kHz}$. This frequency range coincides with the distance of $11 \mathrm{~km}$ in free space. Furthermore, based on Eq. (5) when we take into account the electrical permittivity $(\varepsilon)$ of the surface material as 4.0 , this apparent distance is converted to the depth of $5500 \mathrm{~m}$ below the Moon surface. The transmitted waveform data have already been analyzed by applying the fast Fourier transformation on the ground system, and the power spectrum is directly converted to the range data as shown in the figure. The obtained spectrum shows good performance of the pulse compression method of the sounder system as required. The detail data are shown in Fig. 8, showing that the sounder pulse width transmitted at $200 \mu \mathrm{sec}$ pulse train is compressed to about $0.6 \mu \mathrm{sec}$. The range resolution defined as the $-3 \mathrm{~dB}$ spectral widths in the FFT result is about $180 \mathrm{~m}$ of free space. This value is almost consistent with the range resolution estimated as $200 \mathrm{~m}$ by applying the estimated radiation power spectrum of the sounder pulses discussed in Section 2.6. It is noted; the better range resolution appeared by using the echo simulator did not take into account the effect of the frequency variation of antenna impedance. In Fig. 8, variation of the estimated subsurface echo intensity is plotted by green lines for changing the $\tan \delta$ values of the surface material. Figure 8 also indicates the estimated signal level of echoes from the lunar surface based on the transmitted sounder power of 753 Watts as previously discussed. Compared with the system background noise, it is clear that the present LRS is able to obtain the subsurface echoes from the Moon with a maximum observation range of $5 \mathrm{~km}$ for small loss tangent medium $(\tan \delta=0.006)$. The limit of the observation range is changeable depending on 


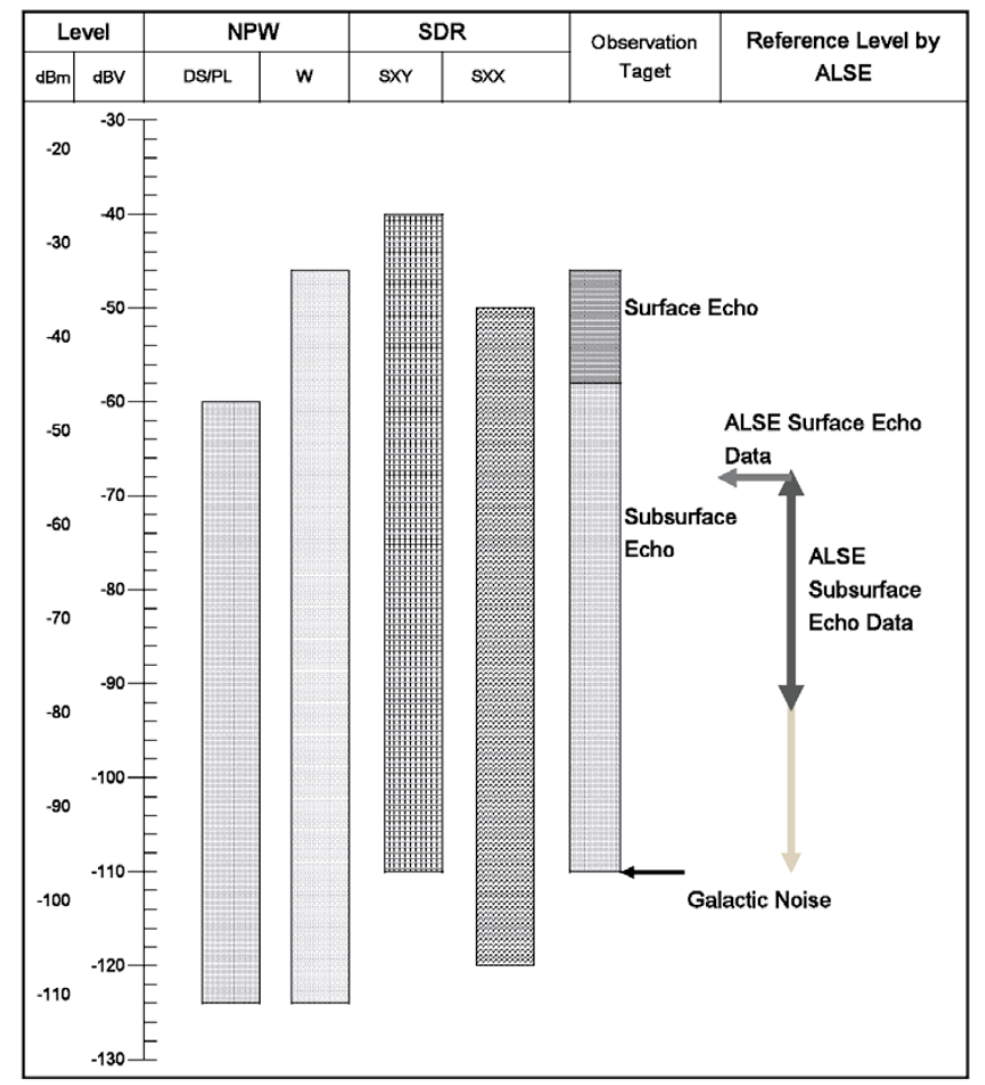

Fig. 9. The level diagram of the LRS receiver for DS mode, PL mode, SDR mode and SDR mode with TR switch operation. The vertical axis shows an equivalent input signal level given as $\mathrm{dB} \mathrm{m}$ and $\mathrm{dB}$ V. The height of the rectangles shows the dynamic range of receivers. The rectangle named as "Observation Target" gives expected intensity range of the surface and sub-surface echoes for the sounder observation by the LRS system. Performance of the ALSE experiment is compared with the LRS system. The colored bar given for the ALSE data also shows detectable echo intensity range for the ALSE receiver; however it was out of range of the photo-film data recording.

the properties of the propagating medium, especially on the loss tangent value as shown in the figure.

To demonstrate the overall performance of the LRS system, including the capability of the passive mode receiver, Fig. 9 shows a level diagram of the LRS receiver for the DS mode, PL mode, SDR mode and SDR mode including the TR switch operation. For the sounder observation mode, when the transmission power of the sounder pulse of 753 Watts is taken into account, it can then be directly compared with the results of the ALSE experiment on-board Apollo 17 (Phillips et al., 1973). Environmental tests were also carried out to verify the reliability of the functions of the LRS system under the environmental conditions at launch and in lunar orbit. These include (1) temperature test, (2) vacuum test, (3) thermal vacuum test, (4) vibration test, and (5) mechanical shock test. In addition to the environmental tests, electromagnetic compatibility (EMC) tests were carried out to evaluate the noise level of the observation instruments as well as the SELENE spacecraft during the on-flight observation (Kumamoto et al., 2008).

\section{Observation Targets of the LRS System}

Based on the verified instrumental capability revealed by the instrumental development, and previous work invoking theoretical predictions of the sounder observation above the surface of the Moon, it is possible to draw an accurate observation of the results as shown in Fig. 10 (modified the results of Kobayashi et al., 2002b). As shown in this figure, along the path of the SELENE satellite orbit, the LRS observation detects clear nadir echoes, and sometimes strong echoes from craters's edge (off nadir echoes). However, when we examine the B-scan plot of the LRS data, it becomes possible to see the echoes of nadir subsurface echoes (Kobayashi et al., 2002b). LRS operations will mainly be controlled by using macro-commands, each of which includes a necessary command group of discrete functions and system parameters. The daily operation will be controlled by executing stored macro-commands depending on the time sequence on-board the SELENE. The orbital motion of the SELENE satellite will be taken into account to define the observation targets along the lunar orbit. Major target regions on the lunar surface have been identified as sown in Fig. 11. As shown in this figure, regional characteristics of the lunar surface are identified as 6 regions depending on latitudinal and longitudinal distribution of the geological characters. It is clear that the low latitude region of the near side (identified as N1, and S1) is characterized by maria and basins as dominant geological features, an area where detection of subsurface echoes is mostly expected. In particular, the region indicated by a red rectangle is an area where the ALSE experiment on-board the Apollo 17 made many interesting findings and left many unsolved problems associated with trends of subsurface echoes (Peeples et al., 1978; Sharpton and Head, 1982; Cooper et al., 1994). Be- 


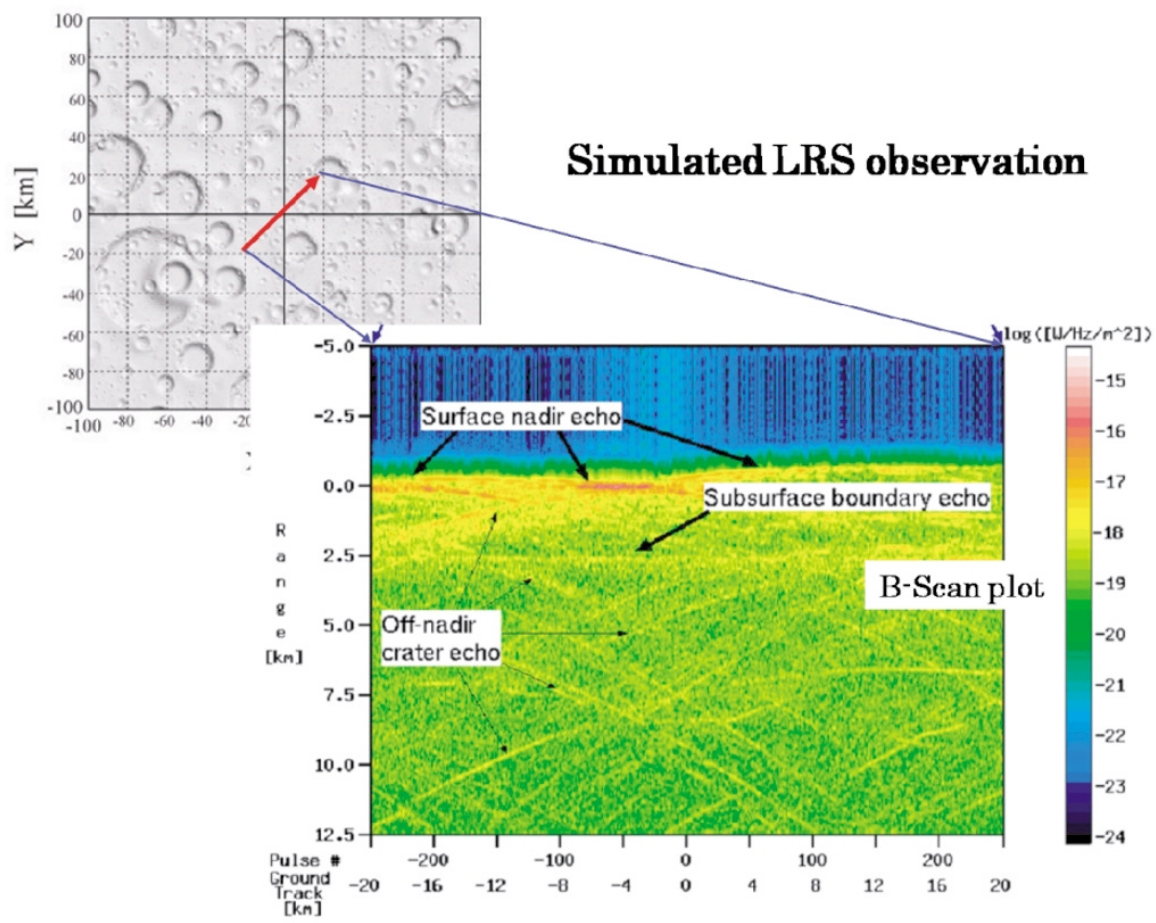

Fig. 10. A B-scan plot of LRS observation result above the synthesized lunar surface (Kobayashi et al., 2002).

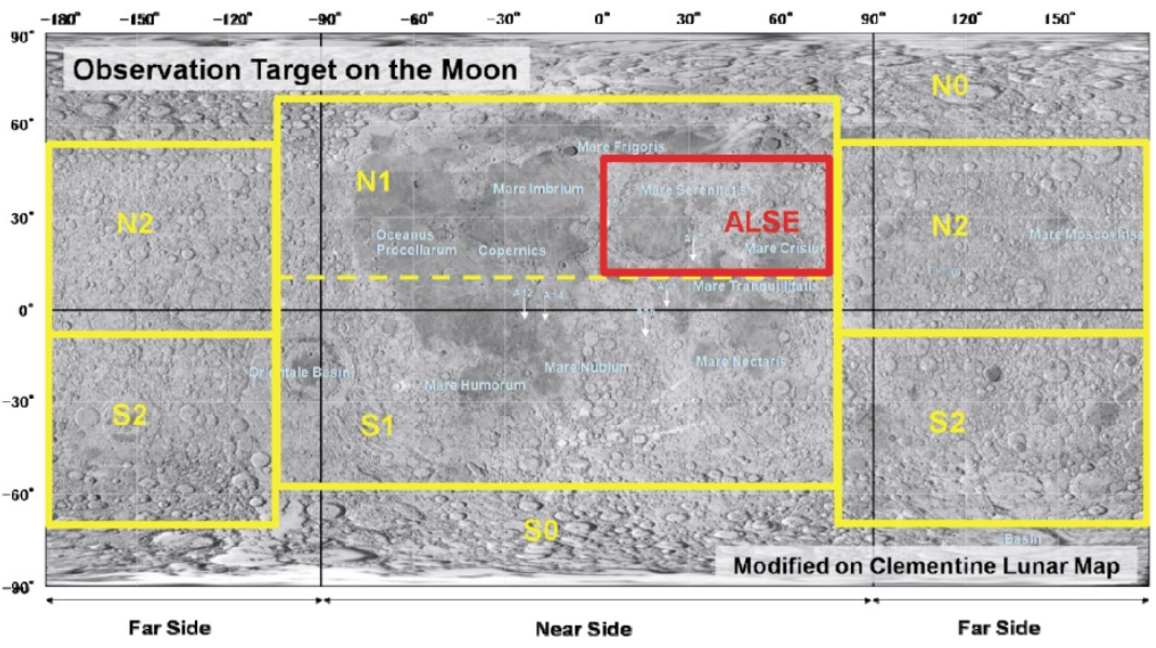

Fig. 11. Major target regions of the sounder observation defined on the lunar surface map obtained by the Clementine (Clementine Lunar Map). The lunar surface is identified as 6 regions; N0, S0 defined as Polar Regions, N1 and S1 defined as nearside regions, and N2 and S2 defined as farside regions. The red rectangle show the most important region of interest where many works have been carried out for the ALSE experiment on-board the Apollo 17.

cause the orbital motion of Apollo 17 was longitudinal, and the orbital character of the SELENE satellite is latitudinal along the polar orbit, LRS observations will make a significant contribution toward understanding the geological structure of this region.

In the lunar farside region, complex highland features seem to prevent clear subsurface echoes for LRS sounder observation; however, some of highlands have the potential for discovery of crypt-mare. As has been pointed out by Yamaji et al. (1998) and Jolliff et al. (2000), sounding of South Pole Aitken is also an important target as a candidate region to find old structures, and the Orientare Basin is a valuable research field to study the origin of the multi-ring crater. As has been discussed by Kobayashi et al. (2002b), even in the highland region, careful data analysis of the LRS results will make it possible to identify subsurface structure below the crater rich terrain.

\section{Discussion and Conclusion}

Results of previous radar soundings by Apollo 17 (for example, Sharpton and Head, 1982; Cooper et al., 1994) have shown that the subsurface layers are clearly detectable above the mare region. It is possible that trends of subsurface layers which have important information about the 
thermal history of the Moon will be detected (Yamaji et al., 1998). It is also possible that buried craters and other structures associated with the activities of volcanoes or meteors before the formation of mare will be found, as was reported by the MARSIS observation on-board the Mars Express (Watters et al., 2006). On the other hand, it seems difficult for radar echoes from the highland to identify the subsurface signals. Kobayashi et al. (2002a) showed that an appropriate averaging method of echo signals has a distinct advantage for finding a subsurface nadir echo signal, because off-nadir clutter echoes are incoherent in nature, while the subsurface nadir echoes tend to be coherent. Thus, the application of data stacking may be the most likely method to overcome the off-nadir echoes. Another approach to reduce off-nadir backscatter echo waveforms is to reproduce backscatter signals from major craters. This method requires precise map of the surface shape of the Moon, however, this will only be available when the SELENE mission completes the global mapping of the lunar surface.

Surface sounding of the Moon by using long radio wave is another target of the LRS system. It is possible to apply SAR analysis by using the waveform data from the LRS observation. As is well known, SAR analysis adds the ambiguity of a mirror image when used in the wide field of view of the antenna system. Indeed, the LRS system uses a dipole antenna. Then when application of the SAR analysis on the observation data is required, several datasets are needed from multiple orbits of the observation with adequate accuracy of the orbital parameters (Kobayashi and Ono, 2007). When the SELENE mission is complete, precise orbital data may be available by using the results from the RSAT and VRAD experiments. When observation position data can be identified with enough accuracy, the SAR analysis may be available to generate a map of the permanent shade region near the South Pole region, and also a map of the Moon surface as derived from log wavelength radio waves.

Acknowledgments. The SELENE mission was conducted by the Japan Aerospace Exploration Agency (JAXA). The authors thank Dr. Takizawa, project manager, and Prof. Sasaki, Project Scientist, for their effort in accomplishing the SELENE mission. The authors are grateful to all the team members of the SELENE mission for their thoughtful discussion to establish the high reliability of the mission instruments. The authors thank Dr. Shibata, Mr. Tanimoto, and Mr. Nara of the Meisei Elecric Co. Ltd. for their efforts to establish the LRS instrumentation.

\section{References}

Cooper, B. L., J. L. Carter, and C. A. Sapp, New evidence for graben origin of Oceanus Procellarum from lunar sounder optical imagery, $J$. Geophys. Res., 99(E2), 3799-3812, 1994

Franklin, C. A. and M. A. MacLean, The design of swept-frequency topside sounders, Proc. IEEE, 57, 897-929, 1969.

Gurnett, D. A., D. L. Kirchner, R. L. Huff, D. D. Morgan, A. M. Persoon, T. F. Averkamp, F. Duru, E. Nielsen, A. Safaeinili, J. J. Plaut, and G. Picardi, Radar Soundings of the Ionosphere of Mars, Science, 310, Doi:10.1126/science.1121868, 1929-1933, 2005.

Jackson, J. E. and E. S. Warren, Objectives, History, and Principal achievements of the topside sounder and ISIS project, Proc. IEEE, 57, 861-865, 1969.
Jolliff, B. L., J. J. Gills, A. Haskin, R. L. Korotev, and M. A. Wieczorek, Major lunar crustal terranes: Surface expressions and crust-mantle origins, J. Geophys. Res., 105(E2), 4197-4216, 2000.

Kasahara, Y., Y. Goto, K. Hashimoto, T. Imachi, A. Kumamoto, T. Ono, and H. Matsumoto, Plasma wave observation using waveform capture in the Lunar Radar Sounder on board the SELENE spacecraft, Earth Planets Space, 60, this issue, 341-351, 2008.

Kobayashi, T. and T. Ono, Estimation of planetary surface roughness using radio sounder A-scope data, J. Geophys. Res., 111, E06S10, doi:10. 1029/2005JE002575, 2006.

Kobayashi, T. and T. Ono, SAR/InSAR observation by an HF sounder, $J$. Geophys. Res., 112, E03S90, doi:10.1029/2005JE002576, 2007.

Kobayashi, T., H. Oya, and T. Ono, A-scope analysis of subsurface radar sounding of lunar mare region, Earth Planets Space, 54, 973-982, 2002a.

Kobayashi, T., H. Oya, and T. Ono, B-scan analysis of subsurface radar sounding of lunar highland region, Earth Planets Space, 54, 983-991, $2002 b$.

Kumamoto, A., T. Ono, Y. Kasahara, Y. Goto, Y. Iijima, and S. Nakazawa, Electromagnetic compatibility (EMC) evaluation of the SELENE spacecraft for the lunar radar sounder (LRS) observations, Earth Planets Space, 60, this issue, 333-340, 2008.

Olhoeft, G. R. and D. W. Strangway, Dielectric properties of the first 100 meters of the moon, Earth Planet. Sci. Lett., 24, 394-404, 1975.

Ono, T., Topside Sounder Observations on-board the Japanese Scientific Satellites, IRI News, 12, 7-11, 2005.

Ono, T. and H. Oya, Lunar Radar Sounder (LRS) experiment on-board the SELENE spacecraft, Earth Planets Space, 52, 629-637, 2000.

Ono, T., H. Oya, A. Morioka, A. Kumamoto, K. Kobayashi, T. Obara, and T. Nakagawa, Plasma waves and sounder (PWS) experiment on-board the PLANET-B Mars orbiter, Earth Planets Space, 50, 213-222, 1998.

Oya, H. and T. Ono, A new altimeter for Mars land shape observations utilizing the ionospheric sounder system on-board the Planet-B spacecraft, Earth Planets Space, 50, 229-234, 1998.

Peeples, W. J., W. R. Sill, W. M. Thomas, S. H. Ward, R. J. Phillips, R. L. Jordan, E. A. Abbott, and T. J. Killpack, Orbital radar evidence for lunar subsurface layering in Maria Serenitatis and Crisium, J. Geophys. Res., 83(B7), 3459-3468, 1978.

Phillips, R. J., G. F. Adams, W. E. Brown Jr., R. E. Eggleton, P. L. Jackson, R. Jordan, W. I. Linlor, W. J. Peeples, L. J. Porcello, J. Ryu, G. Schaber, W. R. Sill, T. W Thompson, S. H. Ward, and J. S. Zelenka, Apollo lunar sounder experiment, NASA Spec. Publ., 330, 22-1-22-26, 1973.

Picardi, G., J. J. Plaut, D. Biccari, O. Bombaci, D. Calabrese, M. Cartacci, A. Cicchetti, S. M. Clifford, P. Edenhofer, W. M. Farrell, C. Federico, A. Frigeri, D. A. Gurnett, T. Hagfors, E. Heggy, A. Herique, R. L. Huff, A. B. Ivanov, W. T. K. Johnson, R. L. Jordan, D. L. Kirchner, W. Kofman, C. J. Leuschen, E. Nielsen, R. Orosei, E. Pettinelli, R. J. Phillips, D. Plettemeier, A. Safaeinili, R. Seu, E. R. Stofan, G. Vannaroni, T. R. Watters, and E. Zampolini, Radar Soundings of the Subsurface of Mars, Science, 310, no. 5756, 1925-1928, DOI: 10.1126/science.1122165, 2005.

Porcello, L. J., R. L. Jordan, J. S. Zelenka, G. F. Adams, R. J. Phillips, W. E. Brown Jr., S. H. Ward, and P. L. Jackson, The Apollo lunar sounder radar system, Proc. IEEE, 62, 769-783, 1974.

Sharpton, V. L. and J. W. Head III, Stratigraphy and structural evolution of southern Mare Serenitatis: a reinterpretation based on Apollo lunar sounder experiment data, J. Geophys. Res., 87(B13), 10983-10998, 1982.

Strangway, D. W. and G. R. Olhoeft, Electrical properties of planetary surfaces, Phil. Trans. R. Soc. London, A., 285, 441-450, 1977.

Yamaji, A., S. Sasaki, Y. Yamaguchi, T. Ono, J. Haruyama, and T. Okada, Lunar tectonics and its implications for the origin and evolution of the moon, Mem. Geol. Soc. Japan, 50, 213-226, 1998.

Watters, T. R., C. J. Leuschen, J. J. Plaut, G. Picardi, A. Safaeinili, S. M. Clifford, W. M. Farrell, A. B. Ivanov, R. J. Phillips, and E. R. Stofan, MARSIS radar sounder evidence of buried basins in the northern lowlands of Mars, Nature, 444, 905-908, doi:10.1038/nature05356, 2006.

T. Ono (e-mail: ono@stpp1.geophys.tohoku.ac.jp), A. Kumamoto, Y. Yamaguchi, A. Yamaji, T. Kobayashi, Y. Kasahara, and H. Oya 